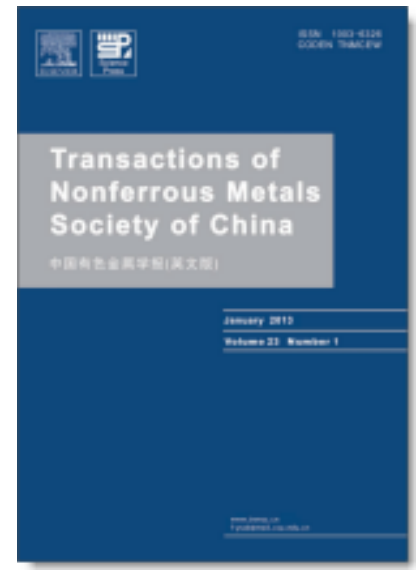

\title{
Germanium transport across supported liquid membrane with Cyanex 923: Mathematical modeling
}

\begin{tabular}{|c|c|}
\hline Journal: & Transactions of Nonferrous Metals Society of China \\
\hline Manuscript ID & TNMSC-2018-1203 \\
\hline Manuscript Type: & Original Article \\
\hline $\begin{array}{r}\text { Date Submitted by the } \\
\text { Author: }\end{array}$ & 09-Dec-2018 \\
\hline Complete List of Authors: & $\begin{array}{l}\text { Kamran Haghighi, Hossein; Amirkabir University of Technology } \\
\text { Department of Mining and Metallurgical Engineering } \\
\text { Irannajad, Mehdi; Amirkabir University of Technology, Mining \& } \\
\text { Metallurgical Eng. } \\
\text { Maria Sastre, Ana; Universitat Politecnica de Catalunya Department } \\
\text { d'Enginyeria Quimica }\end{array}$ \\
\hline Keywords: & $\begin{array}{l}\text { Supported liquid membrane, Cyanex 923, Germanium, Transport, } \\
\text { Mathematical modeling }\end{array}$ \\
\hline Speciality: & Separation process, Modeling \\
\hline
\end{tabular}

\section{SCHOLARONE Manuscripts}




\title{
Germanium transport across supported liquid membrane with Cyanex 923: Mathematical modeling
}

\author{
Hossein Kamran Haghighi a, Mehdi Irannajad *a, Ana Maria Sastre ${ }^{\text {b }}$ \\ ${ }^{a}$ Department of Mining and Metallurgical Engineering, Amirkabir University of Technology, \\ Tehran, Iran \\ ${ }^{b}$ Department of Chemical Engineering, Universitat Politècnica de Catalunya, ESTEIB, Av. \\ Diagonal 647, 08028 Barcelona, Spain. \\ *Corresponding author: iranajad@aut.ac.ir
}

\begin{abstract}
A mathematical model was developed to monitor the facilitated transport of germanium(IV) from oxalic acid solutions through a flat sheet supported liquid membrane (FSSLM) containing Cyanex 923. This model presented a reliable calculation of the extraction constant $\left(K_{e x}=2.057 \times 10^{3}\right.$ 1/mol ${ }^{4}$ ). The FSSLM model was solved according to the extraction reaction, Fick's law, and diffusional transport. Consequently, the overall mass transfer coefficient $\left(K_{\text {org }}\right)$ was found to be $3.84 \mathrm{~cm} / \mathrm{s}$. Using this value, diffusion coefficients for various Cyanex 923 concentrations in the range of 5 to $30 \% \mathrm{v} / \mathrm{v}$ were calculated. Finally, the accuracy of the models was investigated.
\end{abstract}

Keywords: Supported liquid membrane; Cyanex 923; Germanium; Transport; Mathematical modeling

\section{Introduction}

The role of germanium in strategic uses such as semiconductors, catalysts, fiber optics, etc. has caused companies and countries to separate it from various resources [16]. Important primary resources of germanium are classified into zinc sulfide ores and fly ashes. Leachates or 
wastewaters released from plant processing of the mentioned materials may contain germanium. In order to separate germanium from these effluents, various techniques have been developed. Liquid-liquid extraction (LLX) [22], ion exchange [18], ion flotation [9], adsorption [28], precipitation [12], and emulsion liquid membrane (LM) [16], etc. are some of these techniques applied to separate germanium from aqueous solutions. Liquid membrane separation is a type of technique combining the extraction and stripping stages of liquid-liquid extraction processes in a single step. Some advantages such as energy saving, low investment and operational cost due to the lower consumption of extractants have made this technique effective in industrial usages [24]. Bulk LM (BLM), supported LM (SLM), and emulsion LM (ELM) are three types of developed membranes. In flat sheet SLM techniques, a membrane impregnated in a carrier, i.e. commonly a hydrophobic membrane, transports species from a feed phase to a receiving/strip phase based on the chemical potential gradient [24,26,27,29].

Mathematical modeling helps to better recognize the application and performance of SLM systems [21]. It can be useful for designing an effective operation and scaling up SLM systems [15]. The modeling of ion transport through a liquid membrane is carried out according to one of the following assumptions: (a) considering diffusion layers existing in the organic-aqueous interface [14], (b) considering that an organic molecule (carrier) leaves the membrane phase and reacts with aqueous species in the aqueous phase [6], (c) ignoring the presence of static layers formed between the liquid membrane and aqueous phase existing in the feed and strip sides [10]. The third assumption has been considered to develop a mathematical model in the present study. In this assumption, only the diffusion across SLM has taken place in the system. It is noted that an appropriate agitation of the feed/strip phases is necessary to eliminate the aforementioned 
interfacial layer. In the current study, a developed SLM system with well-designed impellers was used to eliminate the interfacial layers.

Several works studied the transport modeling of various species using Cyanex 923 as a carrier. Table 1 shows a summary of these studies. A kinetic model was obtained to describe parameters of the cadmium transport, including diffusions of ions, carrier, and carrier-ions across diffusion layers and interfacial chemical reactions [8]. Alguacil and Alonso (2003) [7] found the flux of chromium transported using Cyanex 923 in an FSSLM system with the basis of a model calculated using Fick's law. A permeation model illustrating the facilitated transport mechanism of iron(III) across a liquid membrane impregnated in Cyanex 923 was developed by Alguacil and Martínez (2000) [4]. Mass transfer resistances and diffusion coefficients were found using this model. The transport model of gold(III) across a SLM using Cyanex 923 diluted in n-decane was used to find resistances and diffusion coefficients [5]. Another model was developed to predict the membrane phase composition containing PC88A and Cyanex 923 in the physicochemical transport of uranium(VI) [17]. A mathematical model showing the transport rate is developed by Sastre et al. (1998) [3]. Based on this model, equations in which a relationship was found between the permeability coefficient and diffusion, equilibrium parameters as well as the concentrations of reagents were described. Furthermore, parameters such as diffusion resistances were calculated by means of the aforementioned model. Recently, Kamran Haghighi et al. (2018) [31] developed a mass transfer model to find transport resistances existing in the membrane phase and the boundary interface layer.

The aim of this paper is modeling the germanium(IV) facilitated transport from neutral media using an organophosphorus carrier called Cyanex 923. The development of a mathematical model for the germanium(II) liquid-liquid extraction resulted in determining the extraction equilibrium 
constant. This constant was the basis of FSSLM modeling. Using this constant, another mathematical model was developed according to the extraction equilibrium equation, Fick's law, and diffusional transport to image the behavior of germanium transport across the membrane. The diffusion and transport parameters were found using this model. The goodness of the obtained models was evaluated by comparing the correlations of experimental and model data.

Table 1. A Summary of a literature survey on species transport modeling using Cyanex 923.

\begin{tabular}{|c|c|c|c|c|c|c|}
\hline Authors & Methods & Species & Diluents & Strip medium & Metho & Refs. \\
\hline Alonso et al. & Kinetics & $\mathrm{Cd}(\mathrm{II})$ & Solvesso 100 & $\mathrm{HCl}$ & FSSLM & {$[8]$} \\
\hline Alguacil et al. & Fick's law & $\mathrm{Cr}(\mathrm{VI})$ & $\begin{array}{l}\text { Cumene \& } \\
\text { Solvesso } 100\end{array}$ & Hydrazine Sulfate & FSSLM & [7] \\
\hline Alguacil et al. & $\begin{array}{l}\text { Empirical } \\
\text { equations }\end{array}$ & $\mathrm{Fe}(\mathrm{III})$ & $\begin{array}{l}\text { Xylene, } \\
\text { toluene, n-decane }\end{array}$ & $\mathrm{NaCl}$ & FSLSM & [4] \\
\hline Alguacil et al. & $\begin{array}{l}\text { Empirical } \\
\text { equations }\end{array}$ & $\mathrm{Au}(\mathrm{III})$ & $\begin{array}{l}\text { and carbon } \\
\text { n-decane }\end{array}$ & $\begin{array}{l}\text { sodium } \\
\text { thiocyanate \& }\end{array}$ & & {$[5]$} \\
\hline Sastre et. al & $\begin{array}{l}\text { Empirical } \\
\text { equations }\end{array}$ & $\mathrm{Au}(\mathrm{III})$ & $\begin{array}{l}\text { Cumene, kerosene } \\
\text { and toluene }\end{array}$ & $\mathrm{HCl}$ & $\begin{array}{l}\text { solid- } \\
\text { SLM }\end{array}$ & {$[3]$} \\
\hline Singh et al. & - & $\mathrm{U}(\mathrm{VI})$ & n-dodecane & $\left(\mathrm{NH}_{4}\right)_{2} \mathrm{CO}_{3}$ & FSLSM & {$[17]$} \\
\hline
\end{tabular}

\subsection{Reagents}

An organophosphorus organic extractant called Cyanex 923 (four trialkylphosphine oxides) with the composition of $93 \%$ was provided by CYTEC Inc., USA. In all experiments, kerosene from Sigma-Aldrich was used to dilute Cyanex 923. A synthetic solution was prepared by dissolving 
germanium(IV) dioxide $\left(\mathrm{GeO}_{2}\right)$ with the purity of $99.998 \%$ (Sigma-Aldrich A.C.S. Reagent) in distilled water. The other reagents used were analar grade from Merck, Germany.

\subsection{Experiments}

In order to find the extraction equilibrium constant of the LLX system, a series of experiments were conducted by shaking organic and aqueous phases with O:A ratio of 1 in separatory funnels by means of a mechanical shaker (SBS Instruments SA, Spain). The time of each experiment was 15 min followed by separating aqueous and organic phases. After the phase separation, a $0.5 \mathrm{~mL}$ sample from the aqueous phases was taken to be analyzed by means of an Inductively Coupled Plasma (ICP) (Agilent 700 Series, US). It is noted that the germanium concentration of organic phases was found by mass balancing. All aqueous phases used in the experiments contained 100 $\mathrm{mg} / \mathrm{L} \mathrm{Ge}$ and oxalic acid of $0.1 \mathrm{~mol} / \mathrm{L}$. Furthermore, the Cyanex 923 composition as the carrier was varied in the range of 5 to $30 \% \mathrm{v} / \mathrm{v}$.

FSSLM experiments were conducted in the cells introduced elsewhere [13]. The feed and receiving cells had volumes of $220 \mathrm{~mL}$ separated with a membrane module in which a flat sheet membrane impregnated with various concentrations of Cyanex 923 was used. The membrane used was a Millipore Durapore poly tetra fluoro ethylene (PTFE) membrane with a diameter of $47 \mathrm{~mm}$ and a pore size of $0.45 \mu \mathrm{m}$. The porosity, membrane thickness, and tortuosity of this membrane were $85 \%, 30 \mu \mathrm{m}$, and 1.18 , respectively [19]. This membrane was impregnated with different concentrations of the organic phase followed by rinsing with water to eliminate the excess organic carrier remaining on the membrane surface. The effective area of the membrane was calculated to be $11 \mathrm{~cm}^{2}$. As mentioned before, in order to eliminate the interfacial layers, solutions in the cells were efficiently agitated with well-organized mechanical impellers. In each experiment, samples 
with volumes of $0.5 \mathrm{~mL}$ were taken from the feed/receiving phases at desired durations followed by analyzing the germanium concentration of the solution by means of ICP (Agilent 700 Series).

Since the kinematic viscosity was used in FSSLM modeling, it was calculated for various concentrations of Cyanex 923 using a "Capillary U-Tube Viscometer" supplied from SCHOTT Instruments. The constant viscometer was determined to be 0.01 by the supplier. Calculations were carried out on the basis of the ASTM D445 standard. In order to find the kinematic viscosity, transit time for various concentrations of the carrier was multiplied by the mentioned constant. To evaluate the dynamic viscosity, kinematic values were multiplied by the corresponding density.

\section{Modeling}

\subsection{Liquid-liquid extraction}

In order to model the extraction of germanium from a solution containing oxalic acid, a series of mass balance and chemical equilibrium equations were considered. In the equilibrium condition, equations corresponding to species reacted in aqueous and organic phases were obtained. In order to obtain these equations, the germanium extraction mechanism of Cyanex 923 from a solution containing oxalic acid should be described. Since Cyanex 923 extracts species as the solvation mechanism, it is predicted that neutral species of germanium are extracted. With respect to the previous works, neutral species of trisoxalato germanates formed in aqueous solutions as in Eq. (1) $[30]$ :

$3 \mathrm{H}_{2} \mathrm{C}_{2} \mathrm{O}_{4}+\mathrm{GeO}_{2} \cdot \mathrm{H}_{2} \mathrm{O} \Leftrightarrow \mathrm{H}_{2} \mathrm{Ge}\left(\mathrm{C}_{2} \mathrm{O}_{4}\right)_{3}+3 \mathrm{H}_{2} \mathrm{O}$

The aim of modeling for the LLX system was to find the extraction equilibrium constant used in FSSLM modeling. For this purpose, a series of experiments were conducted in the carrier 
concentrations of 1-30\%v/v. The overall reaction between trisoxalato germanates and Cyanex 923 can be written as Eq. (2) [30]:

$$
\mathrm{H}_{2} \mathrm{Ge}\left(\mathrm{C}_{2} \mathrm{O}_{4}\right)_{3(a q)}+4 L_{(\text {org })} \Leftrightarrow \mathrm{H}_{2} \mathrm{Ge}\left(\mathrm{C}_{2} \mathrm{O}_{4}\right)_{3} \cdot 4 L_{(\text {org })}
$$

Subscripts $a q$ and org represent aqueous and organic phases, respectively. The extraction equilibrium constant for this reaction is written as Eq. (3):

$$
K_{e x}=\frac{\left[\mathrm{H}_{2} \mathrm{Ge}\left(\mathrm{C}_{2} \mathrm{O}_{4}\right)_{3} \cdot 4 L\right]_{(\text {org })}}{\left[\mathrm{H}_{2} \mathrm{Ge}\left(\mathrm{C}_{2} \mathrm{O}_{4}\right)_{3}\right]_{(a q)}[L]_{e q}{ }^{4}(\mathrm{org})}
$$

Where brackets show the concentration and eq subscript depicts the equilibrium condition. In order to simplify the mathematical formulas, $[\mathrm{L}]_{\mathrm{eq}},\left[\mathrm{H}_{2} \mathrm{Ge}\left(\mathrm{C}_{2} \mathrm{O}_{4}\right)_{3} \cdot 4 \mathrm{~L}\right]_{(\text {org })}$, and $\left[\mathrm{H}_{2} \mathrm{Ge}\left(\mathrm{C}_{2} \mathrm{O}_{4}\right)_{3}\right]_{(a q)}$ are replaced with $L_{e q}, C_{G e, o r g, i}$, and $C_{G e, a q . \text { exp }, i}$, respectively. Obtaining $K_{e x}$ was carried out based on minimizing the sum of squares (SS) attained between the experimental and modeling extraction efficiency. The corresponding calculations were conducted using the solver technique in Excel 2016 software. For this purpose, solver dedicated a value to $K_{e x}$. Using this value, the germanium concentration in the organic phase was again calculated using Eq. (3). Then, the model extraction efficiency can be found using Eq. (4).

$$
\% E=\frac{C_{G e, o r g}}{C_{G e, 0}}
$$

Where $E_{\text {model }}$ and $E_{\text {exp }}$ are the extraction efficiencies obtained from the model and experiments. Finally, the sum of square values based on extraction efficiencies of experiments and model were obtained as Eq. (5):

$$
S S=\sum_{i=1}^{N}\left(\% E_{\bmod e l}-\% E_{\exp }\right)^{2}
$$


Where, $i$ and $N$ depict counter and the number of experiments, respectively. The mentioned dedication continued until the best $K_{e x}$ was found in a condition in which SS between the model and experimental values were minimum.

\subsection{Flat sheet supported liquid membrane}

As mentioned before, the extraction equilibrium constant $\left(K_{e x}\right)$ of the LLX system found using the corresponding model was used in the formulation of the FSSLM system. Matrixes were used in the mathematical programming in the Matlab software as follows:

(a) A matrix includes columns of the germanium initial concentration, Cyanex 923 concentration, the number of samples in each carrier concentration, and the corresponding viscosities.

(b) A time matrix includes times of the taken samples in each condition ( $i$ which shows the initial concentration of the carrier) imported in each row.

(c) A matrix called the concentration matrix containing the germanium concentrations of the feed solution at times mentioned in the time matrix.

Resistances in the interfacial layers have been ignored during the modeling due to the good agitation of solutions by impellers placed close to the membrane phase. According to the literature, the interfacial resistances are usually ignored in rough models [25]. In the present study, the model was created based on Fick's law as in Eqs. (6) and (7):

$$
\begin{aligned}
& J_{G e, i}(t)=K_{o r g} \times C_{G e, o r g, i}(t) \times \mu^{-\alpha} \\
& J_{G e}=-\frac{V}{A} \frac{d C_{G e, o r g}}{d t}
\end{aligned}
$$

Where $J_{G e}$ is the germanium flux through the membrane, $K_{\text {org }}$ represents an overall mass transfer coefficient; $\mu$ is the dynamic viscosity, $\alpha$ is a constant value representing the power of the carrier's viscosity, $V$ is the volume equal to $220 \mathrm{~mL}$ and $A$ is the membrane effective area equal to $11 \mathrm{~cm}^{2}$. 
For easiness, the germanium concentration transported by Cyanex 923 was represented with $C_{G e}$, org.i. In order to create a model, the Matlab 2012 software was used to write a program as shown in Fig. 1 and the following procedure:

(a) The concentration of germanium transported $\left(C_{G e, o r g, i}(t)\right)$ by Cyanex 923 with a specific concentration $(i$, e.g. $i=1$ represents the concentration of $5 \% \mathrm{v} / \mathrm{v}$ ) was calculated at the time of $\mathrm{t}$ with respect to the experimental germanium concentration of the feed phase $\left(C_{G e, a q, \text { exp }, i}\right)$ as the extraction equilibrium reaction represented in Eq. (3). This calculation is as Eq. (8):

$$
C_{G e, o r g, i}(t)=C_{G e, a q, \exp , i}(t) \times K_{e x} \times L_{e q}^{4}
$$

(b) In each loop, fmiccon generated values for $K_{\text {org }}$ and $\alpha$. Using these values, $J_{G e}(t)$ was calculated using Eq. (6). The calculated germanium concentration $\left(C_{G e, a q, c a l, i}(t)\right)$ in the feed phase at the time of $t$ in various experimental conditions (i) was obtained using Eq. (7) and rewritten as Eq. (9):

$$
C_{G e, a q, c a l, i}(t)=C_{G e, a q, \exp , i}(t-1)-\frac{A}{V} \times \Delta t \times J_{G e, i}(t)
$$

In this equation, $C_{G e, a q, c a l, i}(t-1)$ depicts the germanium concentration in the feed solution at the time of $t$ - 1 . At the condition of $t=1$, this concentration shows the initial germanium concentration in the feed phase. Furthermore, $\Delta t$ is the time interval of the calculations (here is $1 \mathrm{~min}$ ).

(c) The objective values of this study are $K_{\text {org }}$ and $\alpha$. Their optimum values were found based on minimization of the sum of squares using the fmincon function (see Fig. 1). After obtaining values of calculated germanium concentrations for a $\operatorname{loop}\left(C_{G e, a q, c a l, i}(t)\right)$, the sum of square (SS) function was calculated from the squared differences between the calculated and experimental values as Eq. (10):

$$
\text { Error }=\sum_{i=1}^{N}\left(C_{G e, a q, c a l, i}(t)-C_{G e, a q, \exp , i}(t)\right)^{2}
$$


(d) If the error function was minimized, the objective values of $K_{\text {org }}$ and $\alpha$ produced using fmincon would be optimized, otherwise, new values were generated to continue calculations according to the aforementioned procedures.

\section{Results and Discussion}

\subsection{Liquid-liquid extraction}

The LLX system was modeled to find the extraction equilibrium constant based on minimizing the sum of squares (SS) for differences between experimental and calculated extraction efficiencies according to the procedure mentioned in the modeling section. To construct the model, experimental parameters such as the carrier concentration, the initial concentration of germanium, and the experimental results such as the extraction efficiency are required. Table 2 illustrates the initial conditions of experiments at room temperature used for modeling. The solver method tried to find a $K_{e x}$ value by which the SS function was minimized. In each step, a proposed $K_{e x}$ was used to calculate the concentration of germanium in the organic solution using Eq. (8) followed by evaluating a value for the extraction efficiency using Eq. (4) called the calculated extraction efficiency $\left(\% E_{c a l}\right)$. Finally, using the optimum value of $K_{e x}$, the $S S$ value was found. According to the results, a value of $2056.83 \mathrm{1} / \mathrm{mol}^{4}$ was obtained for the extraction equilibrium constant of the Cyanex 923 solvent extraction system. In addition, the value of $3.83 \times 10^{-3}$ was found for the minimized SS function. In order to evaluate the accuracy of the LLX model, the plot of extraction efficiency vs. the extractant concentration was constructed as in Fig. 2. As seen in this figure, the model curve has a good fit to the experimental points. The plot of the model extraction efficiency versus experimental results and the regression line showed a correlation coefficient of 0.96 , indicating that model values are close to the values obtained from the experiments. Since a specific membrane was used in all experiments with Cyanex 923, the value of $K_{e x}$ obtained in the LLX 
2

3

4

5

6

7

8

9

system can be used in the SLM system. This supposition is usually considered in similar modeling $[20]$.

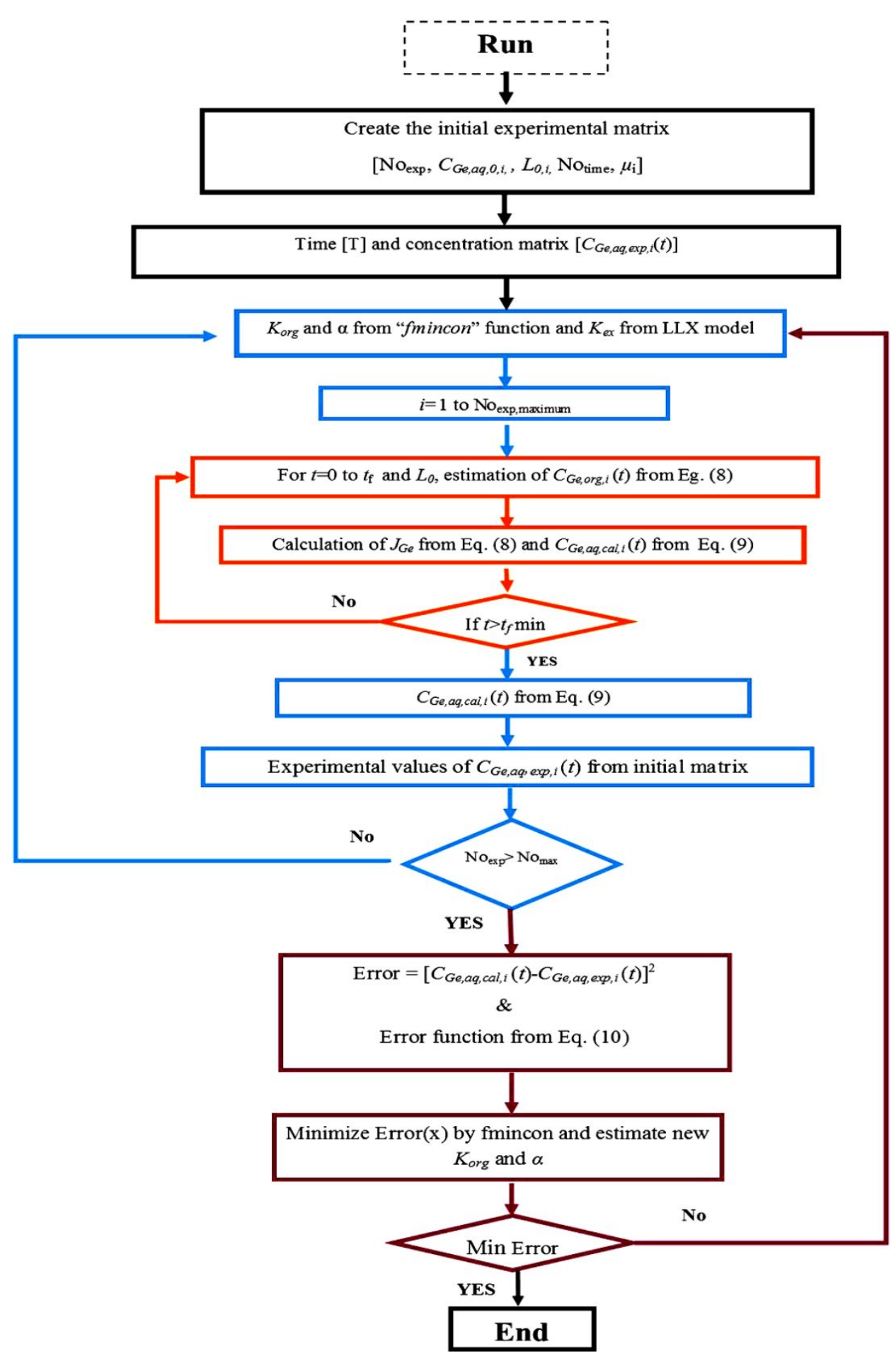

Fig. 1. Flowchart of the modeling procedure used to develop the model of this study. 
Table 2. The initial conditions of the LLX system at room temperature used for modeling

\begin{tabular}{|c|c|c|c|c|}
\hline Cyanex923, \%v/v & $\begin{array}{l}C_{G e, 0, \mathrm{i}} \\
\mathrm{mol} / \mathrm{L}\end{array}$ & $\begin{array}{c}\text { Cyanex 923, } \\
\mathrm{mol} / \mathrm{L}\end{array}$ & $C_{G e, \text { org }}, \mathrm{mol} / \mathrm{L}$ & $\% E_{\text {exp }}$ \\
\hline 30 & 0.0011 & 0.7586207 & 0.00114469 & 99.89 \\
\hline 25 & 0.0011 & 0.6321839 & 0.00114482 & 99.90 \\
\hline 20 & 0.0011 & 0.5057471 & 0.00114056 & 99.53 \\
\hline 15 & 0.0011 & 0.3793103 & 0.0011177 & 97.54 \\
\hline 10 & 0.0011 & 0.2528736 & 0.00103318 & 90.16 \\
\hline 7.5 & 0.0011 & 0.1896552 & 0.00083177 & 72.59 \\
\hline 5 & 0.0011 & 0.1264368 & 0.000595127 & 51.93 \\
\hline 2.5 & 0.0011 & 0.0632184 & 0.00015446 & 13.48 \\
\hline 1 & 0.0011 & 0.0252874 & 4.9284E-05 & 4.30 \\
\hline
\end{tabular}




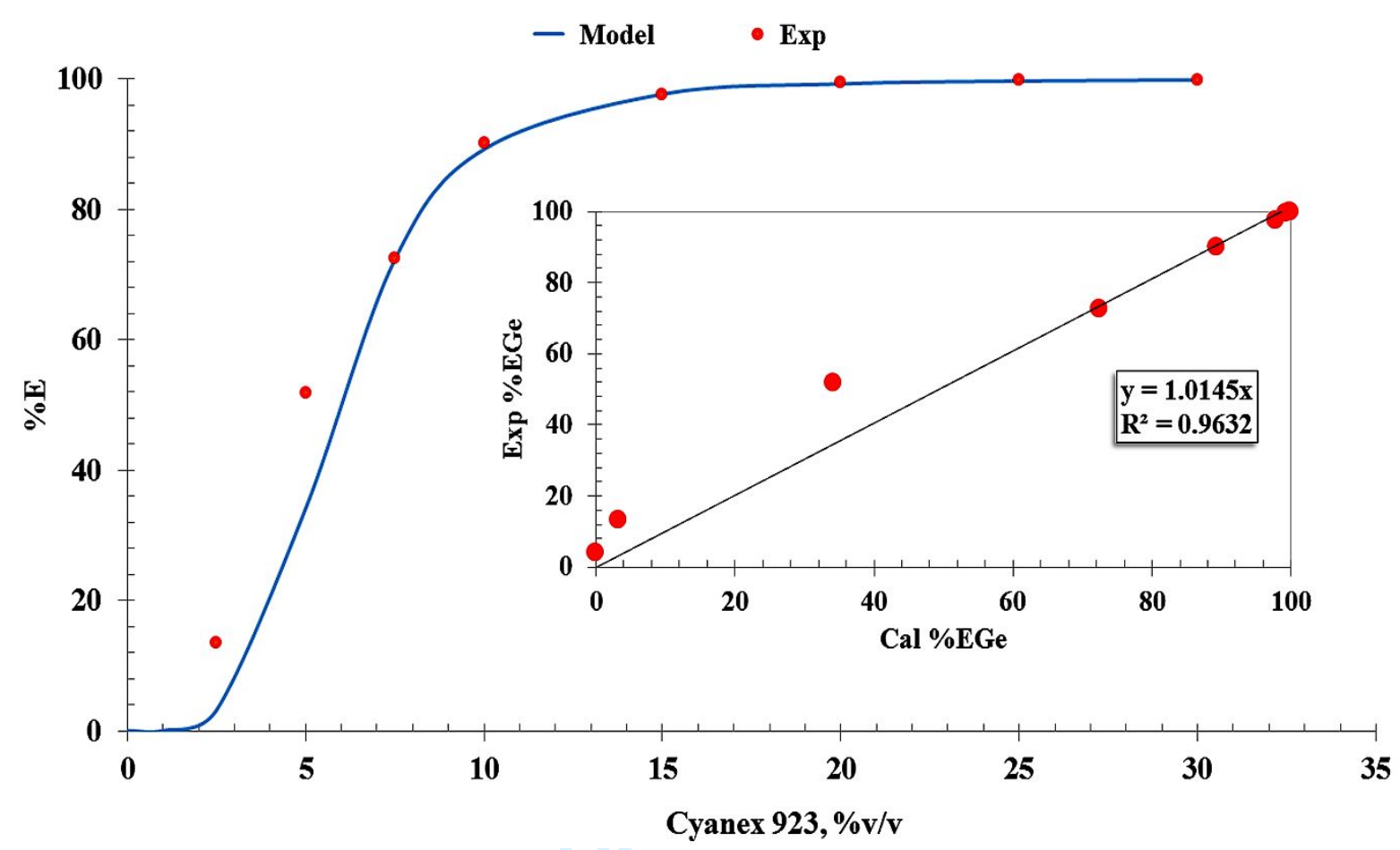

Fig. 2. Model and experimental extraction efficiencies obtained in the LLX system versus Cyanex 923 concentration (the main plot) and the regression line showing the correlation of experimental and model data (the smaller plot).

\subsection{Flat sheet supported liquid membrane}

In order to model the germanium transport across the PTFE membrane containing Cyanex 923, the extraction equilibrium constant, the equilibrium reaction, Fick's law, and diffusional transport, were used. In the equilibrium equation, the extraction equilibrium constant $\left(K_{e x}\right)$ obtained from the LLX model was used. Fig. 1 showed the procedure used in modeling. Experimental data used for the construction of the FSSLM model are listed in Table 3. 
Table 3. The initial conditions used for developing a model for the FSSLM of this study.

\begin{tabular}{|c|c|c|c|c|c|}
\hline$i$ & $\mathrm{C}_{\mathrm{Ge}, 0, \mathrm{i}} \mathrm{mg} / \mathrm{L}$ & $\begin{array}{c}\text { Cyanex923, } \\
\% \mathrm{v} / \mathrm{v}\end{array}$ & $\begin{array}{c}\text { Cyanex } \\
923, \mathrm{~mol} / \mathrm{L}\end{array}$ & $\begin{array}{c}\text { Kinematic Vis., } \\
\mathrm{mm}^{2} / \mathrm{s}\end{array}$ & $\begin{array}{c}\text { Dynamic Vis., } \\
\mathrm{mPa} . \mathrm{s}\end{array}$ \\
\hline 1 & 94.31 & 5 & 0.126 & 2.10 & 2.85 \\
\hline 2 & 94.55 & 10 & 0.252 & 2.35 & 2.38 \\
\hline 3 & 94.23 & 15 & 0.378 & 2.70 & 2.88 \\
\hline 4 & 109.21 & 20 & 0.505 & 3.27 & 3.31 \\
\hline 5 & 86.30 & 25 & 0.631 & 3.76 & 3.42 \\
\hline 6 & 95.04 & 30 & 0.757 & 3.89 & \\
\hline
\end{tabular}

The goal of FSSLM modeling was to find germanium diffusion parameters controlling the transport process. As seen in this table, various concentrations of Cyanex 923 in the range of 5$30 \%$ were used in the PTFE membrane. According to Fig. 1, the germanium concentration in the feed phase and the related times were used in the modeling process. In order to follow the instructions shown in Fig. 1 and introduced in the "Modeling" section, a series of program codes were written in Matlab R2014b software. As seen in this figure, modeling was carried out in two loops; first a loop corresponding to time placed within the main loop, in which the germanium concentration was calculated for each minute and a condition ( $i=$ Cyanex 923 concentration), and second the main loop for changing $i$. For comparing the calculated values with the experimental ones, model germanium concentrations corresponding to times of experimental points were kept. Finally, the optimum values were found when the error function was minimized.

With respect to Eq. (6), the overall mass transfer coefficient $\left(K_{\text {org }}\right)$ found by the program is called the overall $K_{\text {org. }}$. This value was found to be $3.84 \mathrm{~cm} / \mathrm{s}$. Furthermore, the power of the 
carrier's viscosity was obtained to be 0.60 . Hiss and Cussler (1973) [1] reported that the power of the carrier's viscosity for a viscous solvent is about $2 / 3$. This agreement between the values can confirm the accuracy of the model. Moreover, the values of the mass transfer coefficient $\left(K_{m}\right)$ corresponding to different carrier concentrations can be obtained by multiplying the overall mass transfer coefficient by $\mu^{-\alpha}$. Using the mass transfer coefficient for each carrier concentration $\left(K_{m}\right)$, the diffusion coefficient $\left(D_{m}\right)$ can be calculated using the equation reported by Prasad and Sirkar (1988) [2] as Eq. (11):

$K_{m}=\frac{D_{m} \cdot \varepsilon}{\delta . \tau}$

In this equation, porosity, membrane thickness, and tortuosity were shown by $\varepsilon, \delta$, and $\tau$, respectively. The values of $D_{m}$ calculated using Eq. (11) were illustrated in Table 4. As seen in this table, the values of $D_{m}$ decreased with increasing Cyanex 923 concentration. This decrease possibly occurs due to an enhancement of the carrier viscosity. Diffusion coefficients $\left(D_{m}\right)$ obtained were compared with $D_{m}$ achieved in the literature that worked on the facilitated transport of various metals and species through a membrane containing Cyanex 923. Table 5 illustrates this comparison. 
Table 4. The values of mass transfer and diffusion coefficients for various concentrations of Cyanex 923 in the FSSLM system.

\begin{tabular}{|c|c|c|}
\hline Cyanex $923, \% \mathrm{v} / \mathrm{v}$ & $K_{m}, \mathrm{~cm} / \mathrm{s}$ & $D_{m}, \mathrm{~cm}^{2} / \mathrm{s}$ \\
\hline 5 & $4.50 \times 10^{-2}$ & $8.50 \times 10^{-4}$ \\
\hline 10 & $2.28 \times 10^{-2}$ & $4.30 \times 10^{-4}$ \\
\hline 15 & $9.91 \times 10^{-2}$ & $1.87 \times 10^{-4}$ \\
\hline 20 & $3.11 \times 10^{-2}$ & $5.87 \times 10^{-5}$ \\
\hline 25 & $1.36 \times 10^{-2}$ & $2.57 \times 10^{-5}$ \\
\hline 30 & $1.11 \times 10^{-2}$ & $2.09 \times 10^{-5}$ \\
\hline
\end{tabular}

Table 5. The evaluation of the diffusion coefficients in the literature.

\begin{tabular}{|c|c|c|c|c|}
\hline System & Diluent & Support & $D_{m}, \mathrm{~cm}^{2} / \mathrm{s}$ & Ref. \\
\hline Fe-Cyanex 923 $(10 \% \mathrm{v} / \mathrm{v})$ & Xylene & PVDF & $3.3 \times 10^{-6}$ & {$[4]$} \\
\hline Au-Cyanex 923 $(5 \% \mathrm{v} / \mathrm{v})$ & n-decane & PVDF & $9.91 \times 10^{-8}$ & {$[5]$} \\
\hline Cr-Cyanex 923 $(20 \% \mathrm{v} / \mathrm{v})$ & Cumene & PVDF & $7.78 \times 10^{-4}$ & {$[7]$} \\
\hline Cd-Cyanex 923 (10\%v/v) & Kerosene & PVDF & $6.4 \times 10^{-8}$ & {$[8]$} \\
\hline U- PC88A $(0.15 \mathrm{M})$ and Cyanex & n-dodecane & PTFE & $3.90 \times 10^{-6}$ & {$[17]$} \\
$923(0.15 \mathrm{M})$ & & & & \\
\hline Ge-Cyanex 923 $(10 \% \mathrm{v} / \mathrm{v})$ & Kerosene & PTFE & $4.30 \times 10^{-4}$ & This study \\
\hline
\end{tabular}

As seen in this table, in the Fe-Cyanex $923(10 \% \mathrm{v} / \mathrm{v})$ system, first $K_{e x}$ was calculated and then diffusion rates of iron species across the feed diffusion layer-membrane were used to calculate the 
rate of the Fe(III) transport. Using these rates, Fick's first law was applied to find the iron flux through the membrane. The model parameters being the aqueous and organic resistances were found followed by calculating the diffusion coefficient using the obtained organic resistance [4]. Moreover, Alguacil et al. (2001) [5] developed a similar model for the facilitated transport of gold(III) using Cyanex 923 across a PVDF membrane with $125 \mu \mathrm{m}$ thickness, porosity of 75\% and pore size of $22 \mu \mathrm{m}$. In the above mentioned studies, iron(III) and gold(III) were transported as $\mathrm{HFeCl}_{4}$ and $\mathrm{HAuCl}_{4}$ from chloride media using Cyanex 923. In a model developed by Alguacil and Alonso (2003) [7], diffusional fluxes of chromium(IV) at interfacial layers and the membrane phase were determined by two equations. These fluxes had a relationship with corresponding diffusion coefficients. The carrier and the membrane were Cyanex 923 and PVDF with characteristics similar to those explained above. Alonso et al. (2006) [8] used diffusion rates of cadmium species through the feed diffusion layer and the membrane to evaluate the rate of the cadmium transport and to model the facilitated transport of cadmium species through a PVDF membrane using Cyanex 923. The procedures used in the mentioned study were similar to that reported by Alguacil and Martinez (2000) [4]. Since three types of cadmium species namely $\mathrm{CdCl}_{2}$, $\mathrm{HCdCl}_{3}$, and $\mathrm{H}_{2} \mathrm{CdCl}_{4}$ existed in the aqueous solutions, three $K_{e x}$ were calculated and used to determine diffusional flux equations. The values obtained in the aforementioned studies have been listed in Table 5. As seen in this table, most $D_{m}$ values are lower than the diffusion coefficient obtained in the current study. However, the $D_{m}$ value of the Cr-Cyanex $923(20 \% \mathrm{v} / \mathrm{v})$ system is slightly higher than that of this study. The validity of the model was determined by comparing the experimental and calculated data. In this regard, a series of plots corresponding to calculated and experimental results were plotted. Plots were constructed for six Cyanex 932 concentrations mentioned in Table 3. Fig. 3 illustrates plots of germanium concentration in the feed phase 
obtained from experimental and model results as a function of time. The continuous lines and the circular points depict the calculated and experimental data, respectively. With respect to these plots, the germanium concentration decreased in the feed phase over time, meaning that the transport of these species occurred through the FSSLM. The inclination of the experimental points to the model curves shows the accuracy of model points to experimental ones. As seen in Fig. 3(a), the transport rate corresponding to the Cyanex 932 concentration of $5 \% \mathrm{v} / \mathrm{v}$ is very low, as less than $10 \%$ of germanium is transported after $1468 \mathrm{~min}$. However, in the mentioned plot, the model curves have a good tendency to the experimental points. In the other carrier concentrations, the transport rates were gradually increased. Another way to investigate the model accuracy is to show the correlations between experimental and calculated data. This purpose was carried out by plotting the calculated concentrations as a function of experimental results (Fig. 4). According to this figure, correlation coefficients are higher than $92 \%$, showing good agreement between experimental and model data. With respect to the literature, values for correlation coefficients above 0.9 show a good fit with high correlation in a regression plot [11,23]. However, since the transport of germanium corresponding to the Cyanex 923 concentration of $5 \% \mathrm{v} / \mathrm{v}$ is very low, the correlation line could not intercept the origin. Thus, the corresponding correlation coefficient could not be obtainable. 

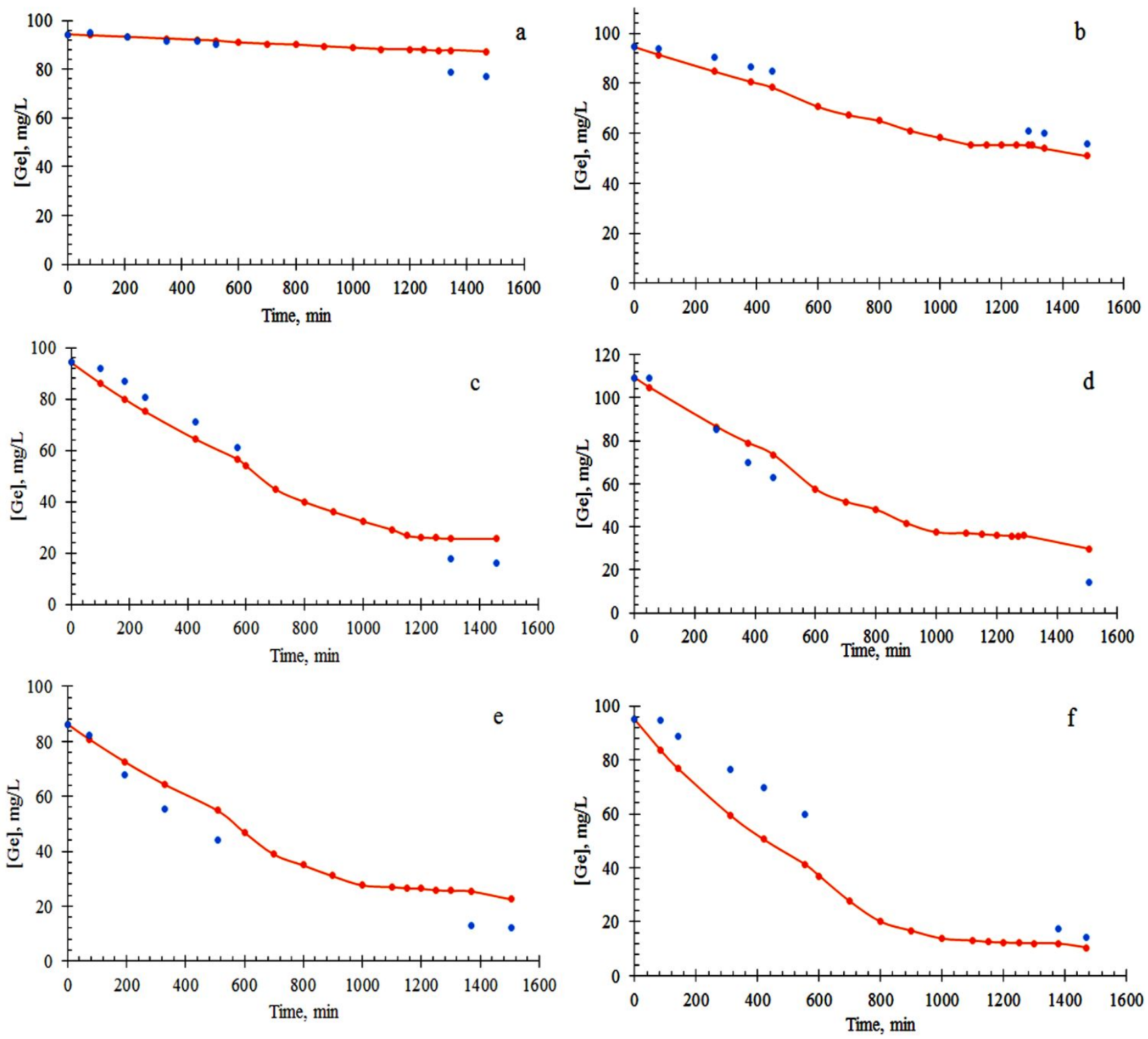

Fig. 3. Model and experimental concentrations of germanium in the feed phase versus time for Cyanex 923 concentrations of (a) $5 \% \mathrm{v} / \mathrm{v}$, (b) $10 \% \mathrm{v} / \mathrm{v}$, (c) $15 \% \mathrm{v} / \mathrm{v}$, (d) $20 \% \mathrm{v} / \mathrm{v}$, (e) $25 \% \mathrm{v} / \mathrm{v}$, and (f) $30 \% \mathrm{v} / \mathrm{v}$. 

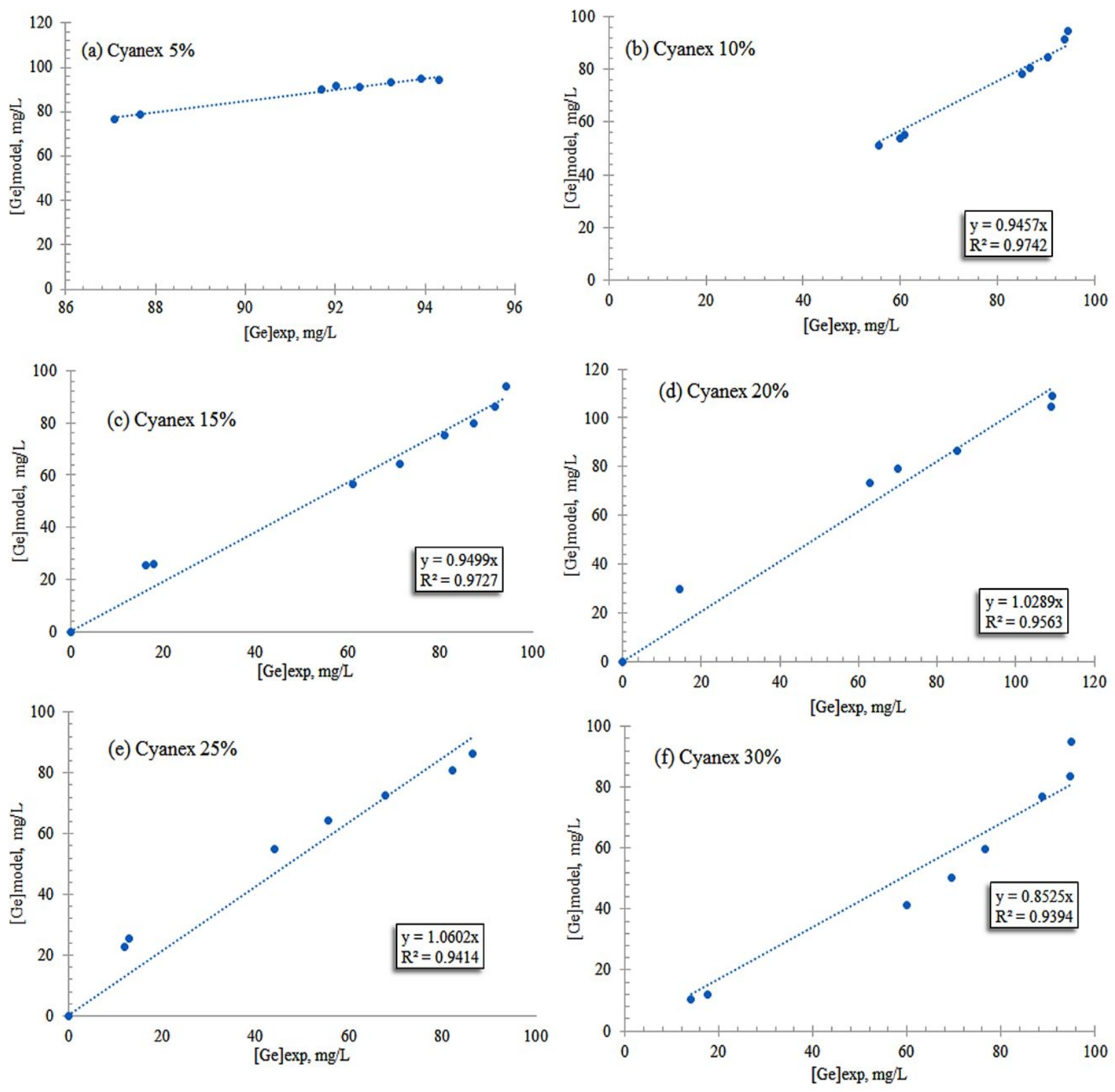

Fig. 4. Regression lines showing the correlation of experimental and model data for Cyanex 923 concentrations of (a) $5 \% \mathrm{v} / \mathrm{v}$, (b) $10 \% \mathrm{v} / \mathrm{v}$, (c) $15 \% \mathrm{v} / \mathrm{v}$, (d) $20 \% \mathrm{v} / \mathrm{v}$, (e) $25 \% \mathrm{v} / \mathrm{v}$, and (f) 30 $\% \mathrm{v} / \mathrm{v}$. 


\section{Conclusion}

A mathematical model was developed to facilitate the transport of Ge(IV) from oxalic acid solutions across FSSLM composed of the Cyanex 923 and a PTFE disc membrane. This model was based on an LLX model, by which the extraction equilibrium constant was found $\left(K_{e x}=2057\right.$ 1/mol ${ }^{4}$ ). The FSSLM model curves fitted to the results obtained from FSSLM experiments for various carrier concentrations. This model resulted in determining the overall mass transfer and diffusion coefficients for the PTFE membranes containing 5\%, 10\%, 15\%, 20\%, 25\% and 30\% (v/v) Cyanex 923. With respect to results, it was possible to fit the model curves to experimental extraction data for all carrier concentrations. As a result, a good agreement between the model and experimental data showed the accuracy of the model. The model can be applied for depth understanding the processes occurring during the facilitated transport of germanium. Moreover, the mentioned models can be valuable for further investigation and designation of hollow-fibre SLM and LLX processes.

\section{Acknowledgments}

This study was performed in the Department of Chemical Engineering, Universitat Politècnica de Catalunya, Vilanova i la Geltrú Campus, Spain. The authors wish to acknowledge Dr. Agustin Fortuny and Dr. Maria Teresa Coll for their help and scientific advice.

\section{Symbols \\ $A=$ membrane effective area $\left[\mathrm{cm}^{2}\right]$ \\ $C_{G e, \mathrm{aq}, 0}=$ initial concentration of germanium in the feed phase $[\mathrm{mol} / \mathrm{L}]$}




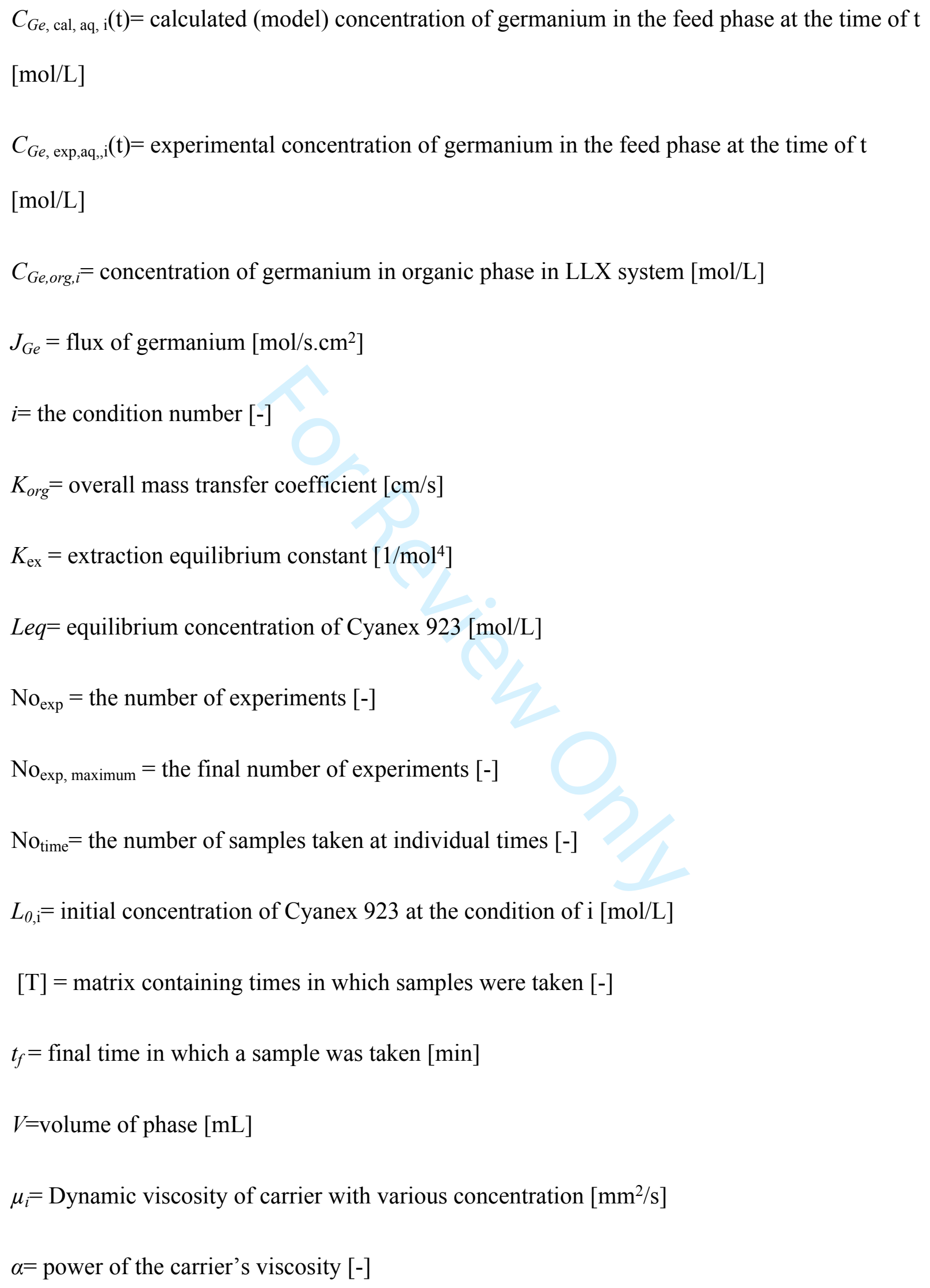




\section{References}

[1] HISS, T.G. and CUSSLER, E. Diffusion in high viscosity liquids [J]. AIChE Journal, 1973, 19: 698-703.

[2] PRASAD, R. and SIRKAR, K. Dispersion-free solvent extraction with microporous hollow-fiber modules [J]. AIChE Journal, 1988, 34: 177-188.

[3] SAStRe, A., MADI, A., CoRtinA, J. and MiRAlles, N. Modelling of mass transfer in facilitated supported liquid membrane transport of gold (III) using phospholene derivatives as carriers [J]. Journal of Membrance Science, 1998, 139: 57-65.

[4] AlgUACIL, F.J. and MARTINEZ, S. Permeation of iron(III) by an immobilised liquid membrane using Cyanex 923 as mobile carrier [J]. Journal of Membrance Science, 2000, 176: 249-255.

[5] AlguaCiL, F.J., Coedo, A.G., Dorado, M.T. and PADILLA, I. Phosphine oxide mediate transport: modelling of mass transfer in supported liquid membrane transport of gold (III) using Cyanex 923 [J]. Chemical Engineering Science, 2001, 56: 3115-3122.

[6] DURAND-VIDAL, S., SIMONIN, J.-P. and TURQ, P. Electrolytes at interfaces [M]. Springer Science \& Business Media, 2001.

[7] ALGUACIL, F.J. and ALONSO, M. Chromium (VI) removal through facilitated transport using CYANEX 923 as carrier and reducing stripping with hydrazine sulfate [J]. Environmental Science \& Technology, 2003, 37: 1043-1047.

[8] Alonso, M., LóPEZ-Delgado, A., SAStRe, A.M. and AlguACIL, F.J. Kinetic modelling of the facilitated transport of cadmium (II) using Cyanex 923 as ionophore [J]. Chemical Engineering Journal (Lausanne, Switzerland: 1996), 2006, 118: 213-219.

[9] Hernández-Expósito, A., Chimenos, J., Fernández, A., Font, O., Querol, X., Coca, P. and Peña, F.G. Ion flotation of germanium from fly ash aqueous leachates [J]. Chemical Engineering Journal, 2006, 118: 69-75.

[10] YANG, Q. and KOCHERGINSKY, N.M. Copper removal from ammoniacal wastewater through a hollow fiber supported liquid membrane system: Modeling and experimental verification [J]. Journal of Membrance Science, 2007, 297: 121-129.

[11] HAMZAOUI, A.H., JAMOUSSI, B. and M'NIF, A. Lithium recovery from highly concentrated solutions: Response surface methodology (RSM) process parameters optimization [J]. Hydrometallurgy, 2008, 90: 1-7.

[12] LIANG, D., WANG, J. and WANG, Y. Germanium recovery by co-precipitation of germanium and iron in conventional zinc metallurgy [J]. J. South. Afr. Inst. Min. Metall., 2008, 108: 715-718.

[13] Rathore, N.S., LeOPOld, A., PABby, A.K., Fortuny, A., Coll, M.T. and SAStre, A.M. Extraction and permeation studies of $\mathrm{Cd}(\mathrm{II})$ in acidic and neutral chloride media using Cyanex 923 on supported liquid membrane [J]. Hydrometallurgy, 2009, 96: 81-87.

[14] DżYGIEL, P. and WIECZOREK, P.P. Chapter 3 - Supported Liquid Membranes and Their Modifications: Definition, Classification, Theory, Stability, Application and Perspectives [M]. Amsterdam: Elsevier, 2010.

[15] Leopold, A.A., Coll, M.T., Fortuny, A., Rathore, N.S. and SAStRe, A.M. Mathematical modeling of cadmium(II) solvent extraction from neutral and acidic chloride media using Cyanex 923 extractant as a metal carrier [J]. Journal of Hazardous Materials, 2010, 182: 903-911.

[16] LIU, F., YANG, Y., LU, Y., SHANG, K., LU, W. and ZHAO, X. Extraction of Germanium by the AOT Microemulsion with N235 System [J]. Industrial \& Engineering Chemistry Research, 2010, 49 : 10005-10008.

[17] SINGH, S.K., MISRA, S., TRIPATHI, S. and SINGH, D. Studies on permeation of uranium (VI) from phosphoric acid medium through supported liquid membrane comprising a binary mixture of PC88A and Cyanex 923 in n-dodecane as carrier [J]. Desalination, 2010, 250: 19-25. 
[18] TorRalvo, F.A. and FernándeZ-PEREIRA, C. Recovery of germanium from real fly ash leachates by ion-exchange extraction [J]. Minerals Engineering, 2011, 24: 35-41.

[19] AdNAN, S., HOANG, M., WANG, H. and XIE, Z. Commercial PTFE membranes for membrane distillation application: effect of microstructure and support material [J]. Desalination, 2012, 284: 297-308.

[20] Kolev, S.D., ST John, A.M. and CATTRALL, R.W. Mathematical modeling of the extraction of uranium(VI) into a polymer inclusion membrane composed of PVC and di-(2-ethylhexyl) phosphoric acid [J]. J. Mem. Sci., 2013, 425-426: 169-175.

[21] Koter, S., Szczepański, P., Mateescu, M., Nechifor, G., Badalau, L. and Koter, I. Modeling of the cadmium transport through a bulk liquid membrane [J]. Separation and Purification Technology, 2013, 107: 135-143.

[22] Kuroiwa, K., OHURA, S.-i., Morisada, S., OHto, K., KaWAKita, H., Matsuo, Y. and FukUda, D. Recovery of germanium from waste solar panels using ion-exchange membrane and solvent extraction [J]. Minerals Engineering, 2014, 55: 181-185.

[23] JUMBRI, K., RozY, M.F.A.-H., AsharI, S.E., Mohamad, R., BASRI, M. and MASOUMI, H.R.F. Optimisation and characterisation of lipase-catalysed synthesis of a kojic monooleate ester in a solvent-free system by response surface methodology [J]. PloS One, 2015, 10: e0144664.

[24] KISLIK, V.S. Liquid Membrane Separation [M]. Berlin, Heidelberg: Springer Berlin Heidelberg, 2015.

[25] LANTTO, J. Analytical model of mass transfer through supported liquid membranes [T]. Sweden: KTH University, 2015.

[26] YANG, X., DUAN, H., SHI, D., YANG, R., WANG, S. and GUO, H. Facilitated transport of phenol through supported liquid membrane containing bis(2-ethylhexyl) sulfoxide (BESO) as the carrier [J]. Chemical Engineering and Processing. Genie Des Procedes. Verfahrenstechnik, 2015, 93: 79-86.

[27] Zaheri, P., Abolghasemi, H., Ghannadi Maraghe, M. and Mohammadi, T. Intensification of Europium extraction through a supported liquid membrane using mixture of D2EHPA and Cyanex272 as carrier [J]. Chemical Engineering and Processing. Genie Des Procedes. Verfahrenstechnik, 2015, 92: 18-24.

[28] CUI, W., WANG, S., PENG, J., ZHANG, L. and ZHANG, G. Catechol-functionalized nanosilica for adsorption of germanium ions from aqueous media [J]. Journal of Sol-Gel Science and Technology, 2016, 77: 666-674.

[29] Mahdavi, H.R., ARZANI, M., Peydayesh, M. and Mohammadi, T. Pertraction of I-lysine by supported liquid membrane using D2EHPA/M2EHPA [J]. Chemical Engineering and Processing. Genie Des Procedes. Verfahrenstechnik, 2016, 106: 50-58.

[30] KamRan Haghighi, H., IRAnnajad, M., Fortuny, A. and SAStre, A.M. Recovery of germanium from leach solutions of fly ash using solvent extraction with various extractants [J]. Hydrometallurgy, 2018, 175: 164-169.

[31] Kamran haghighi, H., Irannajad, M. and Moradkhani, D. Permeation and modeling studies on $\mathrm{Ge}(\mathrm{IV})$ facilitated transport using trioctylamine through supported liquid membrane [J]. Korean Journal of Chemical Engineering, 2018, 35: 53-60. 